\title{
Photovoice an Exercise of Emancipation for Nursing
}

\section{Mg. Sandra Sandoval-Barrientos}

Nurse, Magister in University Education, Academic of Health Department, Universidad de Los Lagos, Chile sandra.sandoval@ulagos.cl

Abstract: Health is a concept that involves not only the physical or psychological well-being of people, but also - among others - appropriating concepts such as empowerment, participation and social mobilization.

In this line, photovoice is a method and at the same time a qualitative research technique that allows pedagogically the possibility that the people themselves can change their environments, situations or structures that limit the healthy experiences in which they are inserted.

In this way, the photovoz facilitates the subjects, to be protagonist of their own health processes, looking for solutions from the resources with which they count and assuming personal and collective responsibilities.

This paper presents in a synthetic way how this methodology is used and some experiences of graduate students and nurses who have successfully used this methodology.

Keywords: Participatory action research, Photovoice, nursing.

\section{INTRODUCTION}

In the framework of qualitative research, the photovoice is constituted as a research methodology action. It uses as a resource the photographic image to visualize, from the perspective of those who live a particular situation, its own reality. Each image is accompanied by a narrative that helps to intentionally work the critical analysis of such graphic representations. The ultimate goal is to empower the participants by generating a change in the way they are situated and living the contexts analyzed. Its application has been documented in an important way in the field of community health and little by little it has begun to gain relevance in the pedagogical field ${ }^{1}$.

This methodology is based critical pedagogy of Paulo Freire's, feminist theory and photographic anthropology. These views contribute elements that enhance the visibility of the voiceless, or the oppressed. Delivering tools to identify themselves with the problems and needs they have, to reflect critically about it, to participate in a collaborative way, to be empowered and to become agents of change in their communities ${ }^{2}$. In this article he makes a brief review on the Photovoice methodology and the most important precepts in health research. Some examples of its use in the field of nursing are given.

\section{DEVELOPMENT}

The qualitative paradigm derives its particularity by focusing its interest and especially its commitment to those who participate in the research. By exposing the "other" point of view, the one that is different from the investigator, from the unknown, from those who have no authorized voice or are invisible. In this way, in this paradigm is intended to give more visibility to the person and not so much to the ailment that afflicts him. Moving away from the biomedical model and bringing health professionals closer to this paradigm, favoring collaborative work ${ }^{2}$. From here, it seeks to seek broad answers that account for the complexity that constitutes each human being and community groups. Approaching and relating professionals sometimes intuitively or intentionally with this paradigm. 


\section{Photovoice an Exercise of Emancipation for Nursing}

In this line appears action - participatory research. A form of self-reflective inquiry that is carried out by the protagonists of particular social situations and has a dual purpose: the generation of knowledge and understanding of the phenomena that live the participants and, on the other hand, the action that involves change of their own social or educational practices. The latter are intended to modify the organization or institution that brings together the participants ${ }^{3}$.

In this framework of action research, the photovoice appears. A participatory research method that harmoniously combines photography, reflection and teamwork. This, in order to generate changes in the space and environment in which the participants are inserted.

This methodology emerged in the 1990s. Caroline Wang and Mary Ann Burris set out to study the well-being of a group of invisible women in China's Yunnan region. They asked this group of women to capture situations in their daily lives, and then critically analyze these images. With this methodology, called in a first instance "Foto novella" they were able to influence local policies and programs related to women in this area ${ }^{1}$.

In the photovoice, it is based on the premise not only scientific but also philosophical that each of the participants is an observer of reality. The sum of these different looks enables a wide range of available action. This methodology proposes to gradually unveil the observer and then impact and change his look. Redesigning its role in this context.

The characteristics of the photovoice methodology, as a form of participatory research, are the following: participatory, the final intention is for people to improve their own social or educational practices; cyclical and recursive, research follows a spiral of cycles that include planning, action, observation and reflection; collaborative, allows the people involved to work in teams in a self-critical way in all phases of the process; stimulates the theorizing of practice; is an emancipatory and political process because it implies changes in the people who participate and are involved in the process².

\section{The Stages that Constitute this Participatory Reflexive Work are the Following:}

First Moment: identification of a topic relevant to the community. Followed by recruitment and selection of participants. This, according to the inclusion-exclusion criteria previously established. Trying to incorporate a broad spectrum of people who take a different look at the phenomenon to investigate.

Second Moment: confirmation and follow-up of the group. Once the participants have been identified and validated, the first call is made. The project is presented, proposing minimum elements and indispensable agreements to participate freely and voluntarily. The protection of ethical aspects is identified ${ }^{4}$.

Participants are also presented. Training them with basic photography tools. It assigns the task of capturing images that "talk" about the subject under investigation.

Third Moment: At the next meeting, the photographs that have captured the participants are put together. Narrating what is observed in the image and contributing in the same way what "provokes" in the observer said image. Analysis of the content of the narrative is generated. In the same way, we analyze the reflection-discussion that is generated in the group. Relevant information that appears in the meetings is recorded in the researcher's field notebook.

Fourth Moment: Share what each member has reflected, adding what has changed or modified in each one regarding the way of seeing, understanding and / or feeling the phenomenon studied. Identify the strengths, certainties, challenges and challenges involved in the subject under investigation, in the concrete context of people.

Fifth Moment: share the work, publishing or exhibiting the images and reflections in spaces that impact. 
Photovoice an Exercise of Emancipation for Nursing

\section{Photovoice and Nursing}

The methodology fotovoz favors the reflection action of those who participate. It has been used mainly in the field of public health and has been guided by groups of health professionals, including nurses ${ }^{5}$.

However, this type of action research has also been applied to groups of nursing professionals and students; seeking to unveil how these groups experience and engage in social, labor or educational situations in which they are inserted.

Among the studies in which nursing students have participated as protagonists are those of Garner et. al., which revealed the perceived labor and personal rewards that students have in the development of their training in India ${ }^{6}$; Kronk et. al., considered to study a community model of research fellowships in an undergraduate course $^{7}$; Narir et. al., studied the use and abuse of alcohol among nursing students ${ }^{8}$; Yonge et to the., discovered the human and rural landscape through the eyes of nursing students and preceptors; ${ }^{8}$ for his part Garner worked this methodology to facilitate cultural competence in students ${ }^{10}$ and as a teaching and learning strategy in undergraduate students ${ }^{11}$.

Some examples of research involving nurses are by Olausson et. al., who, through a phenomenological study, studied the experiences of a group of nurses working in an intensive care unit ${ }^{12}$; for its part, Kirkham applied this methodology to improve the retention of nurses teachers, improving the quality of the work environment ${ }^{13}$; Wahab et. al., studied resilience in a group of nurses ${ }^{14}$; Leipert and Anderson studied rural nursing training through a photophone ${ }^{15}$.

\section{CONCLUSIONS}

Qualitative research is oriented to study in depth some aspect of the complex social reality. It arises as a proposed action research. In it, the image-photography is proposed as a catalyst for the participatory reflection generated by the participants. Through the application of this methodology it is proposed to encourage and nurture the knowledge of the participants regarding a social situation; reflect and discuss personal processes that are common to a particular group; generate changes in the participants and consequently the social and community spaces in which they live.

The fundamental contribution is the emancipation that generates in those who participate in this methodology, giving voice especially to those who are not visible in society.

In the field of nursing, the speaker allows to strengthen the work with community groups and also begins to be used in the pedagogical field helping to unveil meanings given by students and teachers to the formative experiences that sustain them.

\section{REFERENCES}

1. Hergenrather, K.C., Rhodes S.D., Cowan C.A., Bardhoshi G., Pula S. Photovoice as community-based participatory research: A qualitative review. Amer. jourl of heal. behav 2009;33(6):686-698.

2. Kagan, P.N., Smith M.C., Chinn P.L., Philosophies and practices of emancipatory nursing: Social justice as praxis. Vol. 11. Ed. Routledge, New York.2014.

3. Byrne E., Daykin N., Coad J., Participatory Photography in Qualitative Research: A Methodological Review. Jorur. Vis. Met. 2016;4(2):1-12.

4. Hannes K., Parylo O., Let's play it safe: Ethical considerations from participants in a photovoice research project. Inter. Jour. of Qual. Met.2014;13(1):255-274. 
Photovoice an Exercise of Emancipation for Nursing

5. Postma J., Ramon C., Strengthening Community Capacity for Environmental Health Promotion through Photovoice. Jour. Pub. Heal. Nur. 2016;33(4):316-324.

6. Garner S., Perceived Rewards of Nursing Among Christian Nursing Students in Bangalore, India. Jour. of relig. and heal.2015;54(6):2164.

7. Kronk R., Weideman Y. Use of Photovoice to Integrate a Community-Engaged Scholarship Model of Research Into an Undergraduate Clinical Nursing Course. Jour. of Nur. Edu. 2014;53(9):114-S117.

8. Nair J.M., Nemeth.L.S., Sommers M., Newman S., Amella E. Alcohol use, misuse, and abuse among nursing students: a photovoice study. Jour. of addic. Nurs.2016;27(1):12-23.

9. Yonge O., Multiple Lenses: Rural Landscape through the Eyes of Nurse Preceptors and Students. Jour. of Rur. and Com. Devel. 2013;27(1):12-23

10. Garner S. Picture this! Using photovoice to facilitate cultural competence in students. Jour. of Chris. Nurs.2013; 30(3):155-157.

11. Garner S. Photovoice as a teaching and learning strategy for undergraduate nursing students. Nur. Educ. tod.2014;34(10):1272-1274.

12. Olausson S., Ekebergh M., Almerud S. Nurses' lived experiences of intensive care unit bed spaces as a place of care: a phenomenological study. Nur.in crit. Car. 2014;19(3):126-134.

13. Kirkham A. Enhancing Nurse Faculty Retention Through Quality Work Environments: A Photovoice Project. Nurs. Econ.2016;34(6):289.

14. Wahab S.N., Mordiffi S.Z., Ang E., Lopez V. Light at the end of the tunnel: New graduate nurses' accounts of resilience: A qualitative study using Photovoice. Nur. Educ. Tod. 2017; 52:43-49.

15. Leipert B., Anderson E. Rural nursing education: a photovoice perspective. Rur. and Rem. Heal.2012;12:1-4.

Citation: Mg. Sandra Sandoval-Barrientos, "Photovoice an Exercise of Emancipation for Nursing". American Research Journal of Nursing. 2017; 3(1): 1-4.

Copyright (c) 2017 Mg. Sandra Sandoval-Barrientos, This is an open access article distributed under the Creative Commons Attribution License, which permits unrestricted use, distribution, and reproduction in any medium, provided the original work is properly cited. 